\title{
Creatividad y resiliencia. Análisis comparativo de nuevas formas de inserción creativa en contextos de incertidumbre y complejidad
}

\author{
Creativity and resilience. Comparative analysis of new forms \\ of creative integration in contexts of uncertainty and complexity
}

Artículo recibido: octubre de 2010

María Aracelly Quiñones Rodríguez

Artículo aceptado: marzo de 2011

\section{Resumen}

La movilidad humana, característica común en la historia de la humanidad, acentuada en las últimas décadas por multiples factores, es abordada en el presente artículo en dos contextos y grupos de poblaciones específicos y disímiles: los inmigrantes ecuatorianos y colombianos a España y personas en condiciones de desplazamiento forzado, ubicadas en Bogotá, D.C. La creatividad, como posibilidad constructiva del ser humano, es analizada ante los contextos de incertidumbre y complejidad a que se ven abocados (de manera voluntaria o impuesta) quienes conforman la muestra de la investigación.

\section{Palabras clave}

Movilidad humana, incertidumbre, complejidad, creatividad, migración, desplazamiento forzado.

\begin{abstract}
Human mobility, a common characteristic in the history mankind, accentuated in the recent decades by multiple factors, is approached in this article in two contexts and specific populations and dissimilar groups, including Colombian and Ecuatorian immigrants in Spain and people in conditions of forced displacement in Bogotá, D.C.

Creativity, like constructive possibility of human being is analyzed to the contexts of uncertainty and complexity that are doomed to a voluntary or imposed, who make up the sample in the investigation.
\end{abstract}

\section{Keywords:}

human mobility, uncertainty, complexity, creativity, migration, forced relocation.

1 Docente titular de la Universidad Distrital Francisco José de Caldas, doctora en Creatividad Aplicada de la Universidad Autónoma de Madrid, directora del Grupo de Investigación "Cultura, Sexualidad y Educación”, Clasificado en Colciencias en la Categoría B. Correo: arquinon20@yahoo.com 


\section{Introducción}

Con la perspectiva de contrastar los procesos y las formas de adaptación construidas en contextos de gran complejidad, como es el caso de la movilidad humana, en este artículo se presenta una síntesis de los resultados de la investigación titulada "Creatividad y resiliencia: análisis comparativo de nuevas formas de inserción en contextos de incertidumbre y complejidad", realizada por los grupos de investigación "Didáctica y Creatividad" de la Universidad Autónoma de Madrid, España y "Cultura, Sexualidad y Educación” de la Universidad Distrital Francisco José de Caldas de Bogotá, D. C., Colombia ${ }^{1}$.

En ésta investigación, que surge como proyección de la tesis doctoral "Creatividad y resiliencia. Análisis de 13 casos colombianos", realizada en el marco del Doctorado en Creatividad Aplicada de la Universidad Autónoma de Madrid, se abordan particularmente dos casos de movilidad humana. El primero de ellos es el caso de las migraciones a Madrid, España por parte de un grupo de personas de nacionalidades ecuatoriana y colombiana. El segundo, hace referencia a la problemática de personas en condiciones de desplazamiento forzado que, desde diferentes regiones del país, se ubican temporal o permanentemente en Bogotá D. C., Colombia.

Si bien la migración y el desplazamiento forzado son dos problemáticas que poseen factores causales, magnitud, repercusión social, emocional y transformaciones personales significativamente diferentes, son ejemplos de movilidad humana que requieren formas creativas y resilientes para la adaptación e inserción social a los nuevos contextos.

Las condiciones actuales de la sociedad hacen que el ser humano se vea abocado a asumir retos de diferente índole, retos que pueden generar transformaciones radicales en sus condiciones y estructuras emocionales, mentales, psicológicas y sociales.

1 Esta investigación fue realizada en el marco de la $5^{\text {a }}$ Convocatoria de Proyectos de Cooperación Interuniversitaria UAM-Santander con América Latina, en la que participaron los grupos de investigación de la Universidad Autónoma de Madrid, España y la Universidad Distrital Francisco José de Caldas.
El caos, la incertidumbre y la complejidad son características propias de la sociedad contemporánea -independientemente de los contextos sociales particulares- y estas características afectan la dinámica de las sociedades humanas, transformando de manera significativa la vida de las personas.

Con el fin de lograr una aproximación a la comprensión y análisis de las formas creativas que construyen quienes viven la movilidad humana en estas condiciones de incertidumbre y complejidad, en la investigación se generaron las siguientes preguntas orientadoras:

- ¿Cómo han sido las vivencias de los inmigrantes latinoamericanos en Madrid y de las personas en condiciones de desplazamiento forzado en Bogotá, al enfrentar éstos nuevos contextos?

- En sus nuevas condiciones de vida, ¿cuáles son las situaciones de mayor dificultad que viven las personas que conforman la muestra?

- ¿Cuáles son las estrategias creativas que utilizan las personas para lograr una adaptación e inserción a los nuevos contextos?

Integrando las anteriores preguntas orientadoras se formula la pregunta central de la investigación: ¿existen diferencias significativas en las formas de inserción social realizadas por inmigrantes latinoamericanos en Madrid, España, y por personas en condiciones de desplazamiento forzado en Bogotá, D. C., Colombia?

Bajo este panorama, los objetivos propuestos en la investigación se describen a continuación:

\section{Objetivo General}

Identificar y analizar, mediante procesos de contrastación, vivencias y expectativas de personas colombianas y ecuatorianas inmigrantes en Madrid, -España y personas en condiciones de desplazamiento forzado en Bogotá, D. C., -Colombia. 


\section{Objetivos Específicos}

Indagar en los integrantes de la muestra objeto de estudio, las razones y condiciones de llegada y ubicación, particularmente de inmigrantes a España y personas en condiciones de desplazamiento forzado a Bogotá, D.C.

Identificar las emociones asociadas a las vivencias de movilidad, a partir de la percepción personal del grupo de inmigrantes y personas en condiciones de desplazamiento forzado.

Identificar los imaginarios sociales percibidos en los procesos interactivos que se construyen en los diferentes contextos sobre los fenómenos de inmigración y desplazamiento forzado.

Contrastar las formas creativas y de inserción social, elaboradas por las personas que constituyen la muestra o unidad de estudio de la investigación, como estrategias de adaptación a los contextos de incertidumbre y complejidad, propios de ésta forma de movilidad humana.

Consolidar un documento que recopile toda la información y el análisis interpretativo de la investigación para su publicación y divulgación.

La metodología que orienta todo el proceso investigativo se enmarca en un enfoque descriptivo e interpretativo, partiendo de la identificación y evocación de las vivencias de los participantes en los contextos de origen y destino, para posteriormente enfatizar en un trabajo dialógico que posibilita la descripción de carácter fenomenológico de la vida de las personas con la pretensión de comprender los procesos intrasubjetivos e intersubjetivos. De esta forma se logra una aproximación al significado y al sentido de vida que han elaborado los participantes, a partir de la percepción de dos fenómenos de movilidad humana: la migración y el desplazamiento forzado.

La unidad de análisis o población en esta investigación se selecciona en dos contextos particulares de ocurrencia como son: Madrid, España y Bogotá, D. C., Colombia.
La unidad de estudio o muestra está conformada por 95 participantes organizados a partir de las siguientes características:

- 58 inmigrantes, compuestos por 22 ecuatorianos y 36 colombianos, ubicados temporal o permanentemente en España.

- 35 personas en condiciones de desplazamiento forzado, provenientes de diferentes regiones del país y ubicadas en el momento de la realización de la investigación en Bogotá, D.C.

- 2 españoles que dirigen en Madrid los CEPI -Centros Españoles para Inmigrantes-, respectivamente de Ecuador y Colombia y quienes amablemente compartieron las intencionalidades de éstos centros y las diferentes actividades que se orientan para los inmigrantes.

Vale la pena aclarar que el análisis y los resultados de ésta investigación se refieren solamente a las personas que conformaron la muestra; en ningún momento se tiene la pretensión de generalizar resultados. Adicionalmente, al entrevistar o encuestar a los participantes se les manifestó el carácter anónimo de la información solicitada, razón por la cual se omiten nombres de personas o de lugares.

Las técnicas de investigación se centran en la realización de entrevistas de grupos focales y encuestas aplicadas presencial o virtualmente. Esta segunda modalidad se utiliza con un grupo de personas que integraron la unidad de trabajo y que se encontraban ubicadas en ese momento en Madrid.

Después de la sistematización de la información y utilizando matrices simples, cuadros estadísticos y gráficas que consolidan el corpus de la investigación, surgen tres categorías emergentes, en torno a las cuales se realiza el análisis interpretativo.

Esta investigación tiene una duración de 12 meses, lapso comprendido entre los años 2008 y 2009.

\section{Hallazgos investigativos}

En la siguiente parte del artículo y, a manera de síntesis, se presenta el análisis organizado en tres categorías: 
Movilidad humana: perspectivas e intencionalidades. Para iniciar el análisis de esta temática vale la pena aclarar la necesidad de orientar la discusión desde un enfoque multidisciplinar. Lo anterior debido a las grandes dimensiones que engloba la problemática de las personas que presentan alguna vulnerabilidad, dadas las circunstancias mismas de la movilidad humana en el contexto de la investigación, los migrantes y la población en condiciones de desplazamiento forzado.

En la sociedad actual, el fenómeno de la globalización y la dinámica social que ocurre entre los pueblos -en algunas oportunidades de manera espontánea, en otras determinada por diferentes formas de violencia derivadas de circunstancias de carácter social, político, económico o cultural-, surgen conceptos como la multiculturalidad y la interculturalidad que se fundamentan en una pluralidad cultural de orden social, étnico, racial, intelectual, religioso, económico, político y sexual.

La movilidad humana se presenta en la población que se encuentra en condiciones de desplazamiento (independiente o bilateral) de procesos de inmigración y emigración al interior o exterior de las regiones de los respectivos países o entre diversas naciones. Como lo expresa B. McKinley, director general de la Organización Internacional para las Migraciones: "Hoy en día, se estima que existen más de 200 millones de migrantes en el mundo; esto es, más del $3 \%$ de la población mundial, de la cual el 50\% son mujeres. Lo que significa que una de cada 35 personas es un migrante" (2006: 9).

La alteridad, concepto fundamental en este análisis, se basa en el reconocimiento del otro a partir de los procesos identitarios y relacionales de interlocución humana, en donde es fundamental el respeto por lo expresado y sentido por los "otros", en conjunción con una valoración y aceptación mutua de las expresiones y rasgos culturales propios de cada contexto y grupo social. En esta interlocución son determinantes las formas dialógicas que se establezcan entre las partes. Así, para lograr los procesos de alteridad se requiere, desde cada miembro de la sociedad, el respeto por las raíces culturales y las formas de expresión de las mismas, ya sean éstas propias o ajenas. Bajo esta perspectiva, A. Grimson plantea lo siguiente:

Desde una perspectiva histórica y constructivista los espacios nacionales pueden comprenderse como campos de interlocución en los que algunas formas de identificación son legitimadas en los procesos de alianza y conflicto, mientras otras son invisibilizadas. En cada espacio nacional se ha instituido una forma específica de articular u ocultar la diversidad (2000: 16).

En este marco de ideas, es de gran importancia tener en cuenta lo relacionado con los movimientos migratorios y los procesos mixtos de inmigración y emigración, en donde las nuevas condiciones espaciotemporales se constituyen en un contexto simbólico que adquiere significado para la población que se encuentra en condiciones de movilidad, por las mismas proyecciones de un futuro a construir a partir de la integración a las formas de vida propias de la cultura receptora o de acogida, en conjunción con los imaginarios, tradiciones y costumbres que poseen y trasladan los nuevos miembros de la sociedad.

Los movimientos migratorios, entendidos dentro de la perspectiva de Malgesini y Gimenez, (citados por Gómez Crespo, P., et al. 2004): Son desplazamientos masivos de población, de una región a otra (rurales, urbanos, interregionales, etc.) o de uno o varios países a otro u otros. En general, se alude a una cierta continuidad o tendencia en el proceso y no a un traslado coyuntural o puntual (Malgesini, G. \& Gómez, C. 2004: 14).

Los móviles de los movimientos migratorios pueden estar determinados por razones disímiles y particulares; además como grupos humanos, pueden analizarse en diferentes épocas de la historia. Es así como los factores de naturaleza política, económica, religiosa, étnica y racial, a lo largo de la historia de la humanidad, han determinado múltiples formas de ubicación de conglomerados humanos en contextos diferentes a sus lugares de origen. Igualmente, los flujos migratorios pueden estar originados por la violencia en sus diferentes 
formas de expresión, las desigualdades sociales y económicas, la falta de oportunidades de trabajo, estudio, investigación y desarrollo profesional.

Del mismo modo, puede referirse al componente medio ambiental. Así, por ejemplo, eventos naturales como sequías, avalanchas, tsunamis, terremotos, entre otros, pueden generar eventos migratorios que determinan, en las poblaciones, la necesidad de evacuación de los sitios habituales de vivienda y el desplazamiento involuntario, por razones de supervivencia.

En este punto se puede recordar cómo han sucedido, en forma continua, movimientos migratorios en diferentes épocas y latitudes del planeta. Por ejemplo, en los albores de la humanidad, los movimientos migratorios de carácter religioso, registrados en el Éxodo y en el Génesis de la Biblia, de la emigración de los israelitas a Egipto ${ }^{2}$. Igualmente, en épocas posteriores el deseo de aventura y las ambiciones de riqueza se constituyeron en motivaciones económicas que dieron origen a procesos migratorios a América, en las épocas de la Conquista y la Colonia.

Otro ejemplo es la ocupación progresiva que se dio en América del Norte, durante el siglo XIX, por parte de españoles, franceses e ingleses, a partir del descubrimiento de oro y plata en el oeste americano. De la misma manera se pueden referenciar las oleadas de inmigrantes a países de América del Sur, en la etapa de la posguerra, por parte de europeos que se radicaron en países como Argentina, Uruguay, Brasil y Colombia, entre otros.

Igualmente y como se consigna en las memorias del X Congreso Internacional sobre Migraciones (2007), realizado en Loreto, Italia, en octubre de 2007, en el continente asiático están emergiendo y consolidándose nuevos polos de atracción de grandes flujos migratorios a Japón, Corea, Taiwán, Hong Kong y Singapur.

Como se puede observar, las razones y factores de ubicación en nuevos contextos son multicausales. El hecho mas significativo de este tema, desde un

2 Génesis, 46-ss y Éxodo 1, 1-9. análisis de carácter humano y social, son las nuevas formas de convivencia que implican procesos de adaptación de la población que se moviliza, los niveles de satisfacción de sus vivencias, las inconformidades, las proyecciones y la valoración que en general se logra de esta movilidad humana.

Igualmente, en esta inmersión a las nuevas culturas se dan procesos de establecimiento de relaciones vinculares por parte de cada sujeto, ya sea en forma independiente con su núcleo familiar en particular, o en conglomerados humanos y sociales, en general; y son esas vivencias, en oportunidades explícitas, en otras tácitas, negadas o aceptadas, satisfactorias o traumáticas y que se suceden de manera voluntaria o impuestas por las circunstancias, las que favorecen o no la inserción y adaptación a partir de la construcción de nuevos tejidos sociales.

Ahora bien, una característica propia de toda sociedad es su gran riqueza cultural, determinada por la diversidad de grupos sociales o comunidades, agrupadas ya sea por étnias, creencias, partidos políticos, razas, entre otros, que pueden pertenecer a una misma región, territorio o lugar. La existencia de esa gran variedad de grupos sociales, identificados por la pluralidad de sus integrantes y que son constitutivos de un país o nación, conforma la multiculturalidad propiamente dicha.

En la dinámica social, propia de los pueblos, se da un intercambio de formas de expresión de sus culturas. Es allí, justamente, donde se pueden encontrar diferentes posturas ante las personas que viven la situación de movilidad: una de ellas se podría caracterizar por la posibilidad de una interculturalidad que llega a trascender las formas de expresión de los ciudadanos que provienen de diferentes lugares, a partir de una inmersión en los nuevos contextos, es decir, de las condiciones propias de cada cultura que llegan a permear a la otra. En esa diversidad cultural se enriquece tanto el receptor como los nuevos miembros de la sociedad.

Una postura diferente es la que no permite a la población que se moviliza la inserción social, obstaculizando o dificultando de múltiples formas su permanencia, ya sea mediante actos discriminato- 
rios, de exclusión o de agresión, dados los mismos conflictos interculturales que se presentan en ese encuentro de culturas.

Rodrigo Alsina, relacionando multiculturalidad e interculturalidad, presenta las siguientes definiciones: "El multiculturalismo es la ideología que propugna la coexistencia de distintas culturas en un mismo espacio real, mediático o virtual. [...] La interculturalidad está determinada por las relaciones que se dan entre las mismas. [...] La interculturalidad hace referencia a la dinámica que se da entre las comunidades culturales" (Alsina, 1999: 45).

La relación entre estos conceptos determina las formas de apropiación e incorporación de los individuos a las sociedades, en la que pueden presentar o no modificaciones en su estructuración social; transformaciones que a su vez se hacen explícitas en las reacciones de acogida o rechazo de los grupos humanos que se encuentran en los lugares de recepción.

Reina, M. (2007) establece, a partir del análisis de estos términos, la relación e interdependencia que se da entre los mismos: "La interculturalidad que supone la multiculturalidad, refiere al fenómeno del encuentro entre culturas, de sus relaciones e interacciones. La interculturalidad es la situación, el espacio de reunión y comunicación entre varias culturas (1999: 429).

Particularmente y para una mayor claridad, a continuación se establece una diferenciación entre los conceptos migración, inmigrante y emigrante. Las migraciones se pueden conceptualizar como desplazamientos de personas, de conglomerados o grupos humanos que por diferentes razones se alejan de sus lugares habituales de origen o residencia, ya sea en forma temporal, permanente o definitiva.

Son dos los actores que están involucrados en los fenómenos migratorios: el inmigrante, persona que entra a participar en el nuevo contexto; $y$, en sentido contrario, el emigrante, aquel que sale del lugar habitual de residencia o nacionalidad. Igualmente, en el marco de esta investigación se identificarán como contextos de «recepción» o «acogida» los que corresponden al inmigrante y los contextos de «salida» propios del emigrante.

La movilidad humana, particularmente las migraciones, tienen, sin lugar a dudas, grandes repercusiones en los dos contextos de ocurrencia por el impacto y las transformaciones en las personas y en la sociedad en general. Como lo expresa McKinley (2006), El tema migratorio ha ganado importancia y se ha convertido en un factor decisivo en la vida política, social y económica de un mundo caracterizado sobre todo por su movilidad. Los efectos de esta migración en individuos, sociedades y países son profundos y multifacéticos (7).

Otro concepto necesario de clarificar en el marco de esta investigación es el relacionado con los refugiados. La Convención de Ginebra, en el Estatuto de los Refugiados de 1951, propone la siguiente definición: Un refugiado es una persona que tiene un fundado temor de ser perseguida a causa de su raza, religión, nacionalidad, pertenencia a un determinado grupo social u opinión política; y que al encontrarse fuera del país de su nacionalidad no puede o no quiere, debido a ese temor, acogerse a la protección de su país (capítulo 1, artículo 1, numeral 2).

También es considerado como refugiado aquel que deja su país porque "su vida, seguridad o libertad han sido amenazadas por la violencia generalizada, la agresión extranjera, los conflictos internos, la violación masiva de los derechos humanos u otras circunstancias que hayan perturbado gravemente el orden público" (Declaración de Cartagena sobre los Refugiados, 1984).

Un aspecto adicional, de importancia en este análisis, es el relacionado con los procesos de «regularización de extranjeros» que se llevó a cabo en España en los años 2000 y 2001. Allí, la exigencia determinada legalmente para los inmigrantes, era demostrar que se había residido en España por un periodo de cinco años, así fuera en condiciones de ilegalidad. Posterior a este procedimiento obtenían un permiso de trabajo por un año, que podían renovar.

Ahora bien, en el caso del desplazamiento forzado -como una de las formas de movilidad humana 
que tiene grandes repercusiones en la sociedad y que se genera por factores de carácter social, religioso, político y económico- es indispensable tener en cuenta la fundamentación legal, expresa en el contexto colombiano.

La Defensoría del Pueblo, mediante una publicación titulada Desplazamiento forzado en Colombia, expresa claramente las repercusiones de este fenómeno social:

Ha sido tan trascendental la incidencia del fenómeno del desplazamiento en la actual configuración geopolítica, que el mundo conocido no existiría sin el destierro y la reubicación de tantos grupos humanos como consecuencia de los conflictos surgidos a través de los siglos. Luchas y exilio han moldeado la forma de ocupar las regiones, de cimentarlas culturalmente y de transformar a través del tiempo la forma de vida de pueblos enteros (Defensoría del Pueblo, 2001: 18).

En este orden de ideas, los desplazamientos forzados son movimientos en la mayoría de los casos violentos e involuntarios, en los que participan dos actores centrales. El primero de ellos está conformado por quienes ejercen el poder en zonas de enfrentamiento, además, dicho enfrentamiento se produce por el interés de un control territorial, la apropiación y la explotación económica. Así mismo, el principal medio utilizado para el desplazamiento es la violencia manifestada en amenazas, hostigamiento, expulsión, masacres, ataques indiscriminados, apropiación de tierras, exigencia de grandes cantidades de dinero ${ }^{3} \mathrm{y}$ bienes de consumo como son los productos de la agricultura y la ganadería.

El segundo grupo está conformado por personas en condiciones de vulnerabilidad, que regularmente viven en las afueras de las grandes ciudades (es decir, en el área rural) y que pertenecen a grupos étnicos (afro colombianos e indígenas) o a campesinos que poseen o trabajan en grandes extensiones de terreno o en parcelas, lugares de los que son desalojados. A esta forma de utilización de la población civil hace alusión el Observatorio de Derechos Humanos en Colombia (2000), cuando alude

3 En el argot popular se denomina "vacunas" a estas exigencias periódicas de orden económico. a que en Colombia el desplazamiento forzado hace parte de las estrategias que han adoptado los actores del conflicto armado, dentro de las cuales la población civil es utilizada para ganar el control regional militar, político y económico (Boletín núm. 12 , noviembre de 2000).

Algunas estadísticas que dan cuenta del fenómeno del desplazamiento forzado en Colombia son las siguientes:

- A partir de la información recopilada en el $\mathrm{SUR}^{4}$, el gobierno colombiano reporta que entre los años 1995 y 2005, se desplazaron 1.661.284 personas.

- Se considera que el año 2002 ha sido el más crítico por el aumento significativo del número de personas desplazadas.

- La Consultoría para los Derechos Humanos -CODHES, en el informe titulado "2007 Año de los Derechos de las Personas Desplazadas", estima un total cercano a los 3.8 millones de colombianos desplazados durante los últimos 20 años ${ }^{5}$.

El siguiente cuadro permite identificar las cifras globales del desplazamiento forzado en Colombia entre los años 2002 y 2006, según CODHES y SINDEHES.

\begin{tabular}{|c|r|}
\hline AÑOS & \multicolumn{1}{|c|}{ TOTAL PERSONAS } \\
\hline 2002 & 412.553 \\
\hline 2003 & 207.607 \\
\hline 2004 & 287.581 \\
\hline 2005 & 310.237 \\
\hline 2006 & 219.886 \\
\hline TOTAL & 1.437 .864 \\
\hline
\end{tabular}

Tabla 1. Desplazamiento forzado en Colombia 2002 al 2006

Fuente: CODHES y SINDEHES

Experiencias de movilidad humana en España $y$ Colombia. Los factores que generan la movilidad

4 Red de Solidaridad Social.

5 Ver: Consultoría para los Derechos Humanos y el Desplazamiento -CODHES, Conferencia Episcopal de Colombia, Cartagena, febrero 2007. 
humana, para los casos particulares de migración a España y el desplazamiento forzado a Bogotá, D.C., son tan variados y multicausales como personas, grupos humanos y contextos sociales, políticos, económicos, religiosos, étnicos y culturales se puedan identificar.

Para el caso particular de esta investigación se hará referencia, en primera instancia, a ecuatorianos y colombianos que se han ubicado temporal o permanentemente como inmigrantes en España, teniendo en cuenta una serie de características y condiciones que se pudieron obtener en la recolección de la información (mediante entrevistas y encuestas), en los contextos de Madrid y Bogotá, D. C.

El total de participantes en esta investigación son 95, los cuales están organizados de la siguiente manera:

- 58 inmigrantes (22 ecuatorianos y 36 colombianos), ubicados temporal o permanentemente en España.

- 35 personas en condiciones de desplazamiento forzado, ubicadas en Bogotá, D.C., provenientes de diferentes regiones del país.

Adicionalmente se entrevistaron 2 españoles que dirigen en Madrid los CEPI -(Centros Españoles para Inmigrantes)-, respectivamente de Ecuador y Colombia.

Las gráficas 1, 2 y 3 muestran los porcentajes de participantes según la distribución por género (femenino y masculino), en cada uno de los grupos objeto de investigación, a saber: inmigrantes ecuatorianos y colombianos en España y personas en condiciones de desplazamiento forzado en Bogotá, D. C. Sin constituirse en una diferencia altamente significativa, se puede observar que en cada uno de los tres grupos la presencia del género femenino es levemente superior a la del género masculino.

La población más joven que emigra a España, en esta muestra, corresponde a ecuatorianos en edades comprendidas entre los 20 y los 30 años. Mientras que en la población colombiana el rango más alto corresponde a personas entre 30 y 50 años.
Por otro lado, en el grupo de personas en condiciones de desplazamiento forzado se presenta un alto porcentaje (80\%) en el rango de personas entre 30 y 50 años.

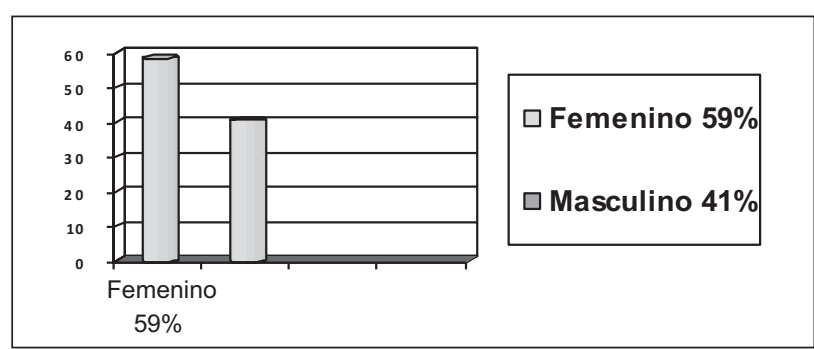

Gráfica 1. Distribución por género de ecuatorianos inmigrantes en España participantes en la investigación

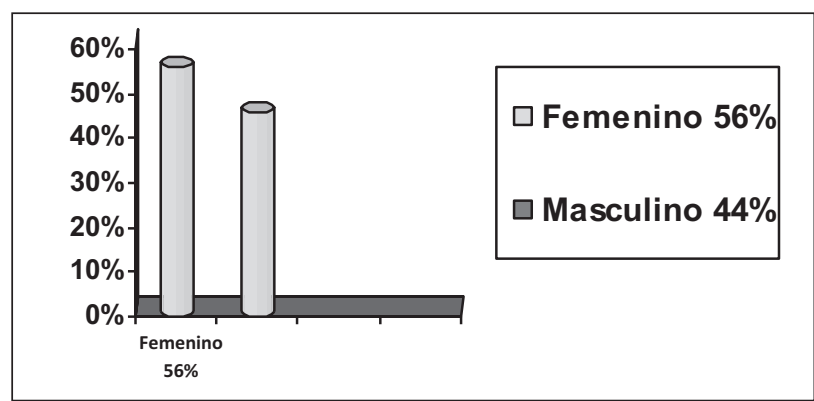

Gráfica 2. Distribución por género de colombianos inmigrantes en España participantes en la investigación

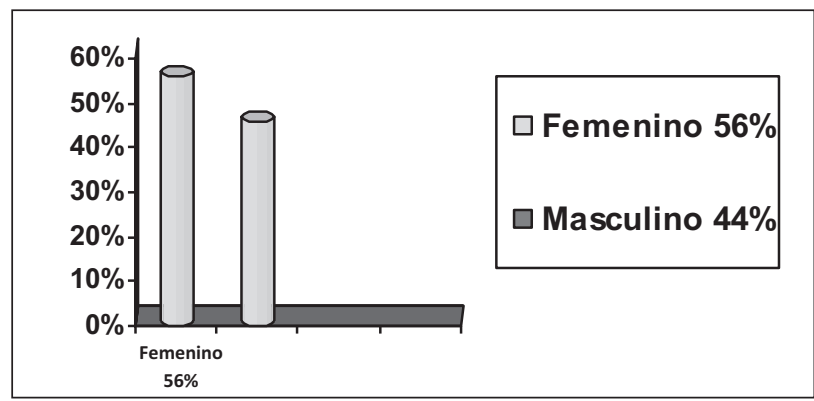

Gráfica 3. Distribución por género en personas en condiciones de desplazamiento forzado participantes en la investigación 


\section{Similitudes y diferencias}

\section{Movilidad humana: ¿imposición o decisión?}

La movilidad humana, de manera general, puede estar determinada por dos motivos fundamentales: en primera instancia son actos conscientes y voluntarios en los que las personas tienen objetivos previamente establecidos y orientan sus acciones a la consecución de los mismos. Un segundo factor está determinado por las imposiciones que de manera abrupta hacen que las personas se tengan que movilizar. En este segundo grupo, se pueden observar razones fundamentales como la obligatoriedad, el destierro o la expulsión.

Los factores causales y particulares que dieron origen a estos ejemplos de movilidad humana se diferencian de manera significativa. Estas diferencias se pueden agrupar en dos grandes campos, organizados en torno al sentido y significado que tuvo la experiencia de movilidad para las personas participantes.

En el primer grupo se puede identificar como, en la mayoría de los casos, las situaciones de migración a España, tanto por ciudadanos ecuatorianos como por colombianos, estuvo mediada por la motivación de lograr mejores condiciones de vida. Sin embargo, si bien las necesidades de orden económico son los principales determinantes que motivaron a las personas a iniciar un proyecto temporal o permanente de una nueva vida en contextos diferentes a sus lugares de origen o residencia, se realizan acciones voluntarias con decisiones propias en las que la incertidumbre que acompaña a estas decisiones permite vislumbrar la probabilidad de una estancia tranquila y próspera, siendo conscientes, a su vez, de la eventualidad de riesgos y dificultades, de la soledad o del fracaso.

Ante las situaciones descritas con anterioridad, la persona está directa o indirectamente preparada porque, en el momento de tomar la decisión, -ha tenido que analizar las implicaciones de ubicarse en otro país, ha madurado la idea- al realizar los procedimientos legales exigidos como ciudadano migrante con los trámites de salida y entrada a los respectivos países, los requerimientos para una ubicación, la atención y satisfacción de necesidades personales que debe asumir lejos de su patria y de sus relaciones vinculares básicas como familia y amigos, las posibilidades de encontrar un trabajo estable y bien remunerado o el riesgo de la inestabilidad o de la explotación laboral. Son, en esencia, acciones conscientemente analizadas y decididas.

Por el contrario, en la problemática del desplazamiento forzado, como ejemplo de movilidad humana, en ningún caso se presentó una decisión intencional previa, mucho menos el ejercicio de la propia voluntad; allí, hablamos de un hecho impuesto, determinado por una razón fundamental, urgente y prioritaria de tener que salvaguardar la propia vida y la de los integrantes de sus familias.

En suma, se trata de una acción de destierro y desarraigo, atentatoria, caracterizada por una total vulneración de los derechos humanos; un evento acompañado por la violencia, el maltrato y la destrucción; es el manejo indiscriminado del atropello contra seres humanos que teniendo condiciones para una vida favorable y próspera en sus contextos de origen, se ven obligados a un éxodo regularmente inmediato y a una posterior ubicación en lugares desconocidos sin condiciones de seguridad o estabilidad, con el agravante del estigma social, propio del desplazamiento forzado.

Impacto afectivo y emocional: huellas psicosociales. $\mathrm{La}$ afectividad, desde un enfoque holístico y como una de las dimensiones del ser humano, determina -como su nombre lo indica la capacidad de «afectación» o impacto de orden psicológico, físico, emocional, cognitivo y moral. La emoción como reacción subjetiva incide en el reconocimiento del sí mismo como sujeto, de sus capacidades y limitaciones y, a su vez, le permite direccionar las acciones tendentes a la solución de problemas significativos, en los diferentes entornos de actuación en los que participa. Todo lo anterior cumple una función preferencialmente de orden adaptativo.

Por las emociones el ser humano se autoconoce y determina, siendo fundamental el autoconcepto y la valía personal y es, a partir de ellos que se dina- 
mizan los procesos cognitivos y, como lo expresa Manz (2005),

\begin{abstract}
Las emociones tienen la capacidad de ayudar al ser humano a enfrentarse con éxito a la incertidumbre, a visualizar un futuro positivo y acelerar la toma de decisiones. Las emociones también pueden contribuir a que se tienda un puente entre lo racional y lo irracional, a conseguir una sensación de relevancia personal, así como a facilitar la adaptación personal y el cambio (28).
\end{abstract}

En los casos de movilidad humana, abordados en la investigación, las emociones se presentan de múltiples maneras porque los estímulos desencadenantes de las mismas adquieren un valor y significado de manera particular para cada sujeto, de acuerdo al impacto de las experiencias, al contexto en que éstas ocurren y a la posibilidad de lograr una motivación personal que impulse a la acción, así los episodios sucedan en ambientes de caos, incertidumbre y complejidad.

De esta manera y en forma general, se pueden clasificar los episodios determinantes de las emociones de los participantes en la investigación, en dos grandes grupos:

Situaciones de agrado que dan origen a estados emocionales propios de la satisfacción de las metas alcanzadas, de experiencias exitosas y de momentos gratificantes. Es así como en el tema de los migrantes a España, el significado y trascendencia que tiene la obtención de trabajo y la consecuente posibilidad de ayuda a sus familiares, mediante el envío de remesas a los lugares de origen, es uno de los principales motivos que desencadenan emociones de agrado manifestadas mediante la alegría y una amplia gama de expresiones de afecto, comprensión, amor y ternura.

De la misma manera, el otorgamiento de la documentación que legaliza la estancia en España, ya sea para trabajo, estudio o turismo, son motivos que, en segundo lugar, generan emociones significativas y placenteras. Estas metas logradas, que implican satisfacción y triunfo, se convierten en un motor que impulsa a la generación de nuevos objetivos, entre los que se encontraron: el mejorar las condiciones laborales, estudiar para una cualificación intelectual y profesional, viajar como oportunidad de conocimiento de otras culturas, regiones y grupos humanos; estos fueron los más reiteriativos, según los testimonios de los participantes. Todo lo anterior, está acompañado de estados emocionales, caracterizados por la alegría, el disfrute, el bienestar y la tranquilidad.

En otro orden de ideas, el sentir el apoyo y respaldo de personas y grupos, fue igualmente gratificante ante el hecho de lograr una liberación de estados de angustia y ansiedad porque se llevaba a cabo una transformación en las condiciones de vida, particularmente ante problemas de soledad, hambre y enfermedad, como ejemplos significativos, logrando de esta manera espacios y momentos de armonía y seguridad personal.

Vale la pena destacar que las personas identificadas y reconocidas como soportes a los que, sentían, podían acudir, fueron en orden de selección en los testimonios brindados, compatriotas o personas de los mismos lugares de origen, es decir, colombianos y ecuatorianos que proporcionaron acogida, protección y respaldo en momentos de aflicción, soledad, abatimiento y especialmente cuando vivieron problemas de orden laboral, de alimentación o de vivienda.

Igualmente los españoles fueron identificados como personas que en muchos casos brindaron comprensión y apoyo, fundamentalmente ante dificultades relacionadas con el campo laboral.

Instituciones como los Centros de Participación e Integración de Inmigrantes -CEPI, particularmente los CEPI colombiano y ecuatoriano, fueron instituciones que proporcionaron espacios reconocidos por el apoyo desinteresado, la orientación y asesoría oportuna para el manejo de problemáticas de carácter legal, laboral y educativo; allí se destaca, especialmente, el ambiente cálido de acogida y preocupación por el bienestar emocional de quienes acudían a ellos.

Fernández-Lasquetty, titular de la Consejería de Inmigración, en la Revista Fusión Latina, analiza 
el significado que los inmigrantes tienen para Madrid, opinión que permite comprender y a su vez visualizar las acciones que se han implementado y proyectado con la población de inmigrantes.

\begin{abstract}
Somos concientes de las necesidades que existen y las opciones tanto de los inmigrantes como de los madrileños, y creemos que la vía más adecuada para la integración del inmigrante consiste en mirar a cada inmigrante como lo que es: como una persona libre, con derechos propios, con personalidad propia, con intereses diferentes, con ideas diferentes, que vienen aquí a conseguir, con trabajo y esfuerzo un futuro mejor para sí mismos y para sus familias.
\end{abstract}

La meta de la Consejería es lograr que los inmigrantes que llegan a Madrid se sientan como en casa y los madrileños que les reciben se sigan encontrando como en casa, y que todos juntos compartamos un cuerpo de valores, de convicciones profundas en torno a lo que es la sociedad, reglas de comportamiento y leyes que no son sólo nuestras, sino también de aquellos que llegan a vivir y a trabajar entre nosotros (Fernández-Lasquetty, 2007: 38).

Ahora bien, en el caso de las personas en condiciones de desplazamiento forzado se pueden identificar estados emocionales agradables, en un tiempo posterior a la experiencia traumática de dicho desplazamiento. Los principales móviles que dieron origen a las emociones agradables están relacionados fundamentalmente con el reencuentro con los seres queridos provenientes de diferentes lugares, en el logro de trabajos que les permitía una seguridad personal y la satisfacción de necesidades básicas.

Bogotá fue identificada por muchos de los entrevistados como una ciudad de oportunidades para iniciar una nueva vida, pero especialmente para brindar a los hijos amplias posibilidades de estudio y superación.

Una situación altamente reconocida y que genera un sentimiento de agrado y estabilidad para este grupo de participantes, fue el apoyo oportuno de entidades gubernamentales y de distintas ONG, mediante programas que atienden problemáticas a nivel personal y familiar, capacitación laboral, préstamos para la organización de microempresas y la obtención de vivienda. Todo lo anterior generó en las personas satisfacción, bienestar, tranquilidad y un sentimiento de agradecimiento.

Un segundo grupo, hace referencia a situaciones desagradables que tambien fueron identificadas por los participantes en la investigación, tanto por migrantes como por personas en condiciones de desplazamiento forzado, a partir del reconocimiento y recuerdo de situaciones y experiencias de una connotación negativa y preocupante por la dificultad que implicaba y por el significado doloroso e impactante de estímulos de naturaleza interna o externa a los sujetos.

Cyrulnik (2003), plantea, al respecto, la importancia y relación de las emociones con los episodios que impactan y maltratan a los sujetos, junto con el significado que tienen para las personas estos acontecimientos.

En la representación del hecho, es donde nace la emoción que provoca el acontecimiento. Lo que el herido piensa de lo que le ha ocurrido, y el sentimiento que eso le hace experimentar, dependen tanto del relato que se cuenta, como del relato que elabora para los demás, narraciones a las que habrá que añadir el relato que confeccionen estos últimos. El sentimiento atribuido al acontecimiento nace en la confluencia de todos estos mundos intersubjetivos (136).

A continuación, se presenta un breve recuento de estas experiencias y las reacciones emocionales más significativas que generaron.

Los móviles del desplazamiento forzado y las situaciones asociadas al éxodo, hacen que las personas tengan el recuerdo de estados emocionales caracterizados por la tristeza, el dolor, el abatimiento.

El impacto personal y social, propio del destierro a que son sometidas las personas que han estado en condiciones de desplazamiento forzado, implica una ruptura con las relaciones vinculares, con los espacios, con las costumbres propias de la cultura, situaciones que se manifiestan a nivel personal, intrafamiliar o extrafamiliar. Son episodios en los que las personas se sienten ultrajadas, maltratadas, ofendidas y despreciadas; todo lo anterior, impli- 
ca la necesidad de una atención profesional por el estrés postraumático propio de las situaciones violentas en que se presentan estos hechos del desplazamiento forzado.

Es común, en todos los eventos mencionados, que surjan estados emocionales de miedo, temor, ansiedad, angustia, culpa, impaciencia, desasosiego e infravaloración; estados que repercuten -como se observó en muchos casos- en alteraciones de naturaleza psicosomática. Es así como se presenta un alto porcentaje de personas en condiciones de desplazamiento forzado, en quienes, a partir de la somatización de la ansiedad y la angustia, se ha dado origen a alteraciones de salud, siendo una de las más significativas la presencia de cáncer.

Una de las poblaciones más afectadas por la problemática del desplazamiento forzado la conforman los niños, en tanto las experiencias que viven a temprana edad, deja una huella imborrable y de gran trascendencia por las consecuencias en su desarrollo emocional, cognitivo y moral ante los episodios vividos.

En el informe "Millones no vistos: La catástrofe del desplazamiento interno en Colombia" de la Delegación del Women's Commissions, en uno de los temas tratados como "Estado de la situación", se hace alusión a la problemática particular del niño en condiciones de desplazamiento forzado.

Los desplazamientos de menores de edad limitan sus oportunidades para el desarrollo personal: los traumas se asocian a la violencia que precede generalmente los desplazamientos, el cambio precipitado en la administración de su tiempo y espacio, y el desmembramiento del núcleo familiar proporciona espacio para una nueva situación aún más hostil. A esta lista se deben agregar los efectos de la segregación y estigmatización a los niños, que tiene un impacto en el desarrollo de su autoestima (Women's Commissions for Refugee Women and Children, 2002: 28).

Ahora bien, en el caso de los migrantes ubicados en España, también se encontraron situaciones significativas que impactanron en sentido negativo y originaron estados emocionales caracterizados por el temor, la tristeza, la angustia, el miedo y la ira.
Algunos ejemplos están relacionados con las condiciones laborales de explotación, por las jornadas extensas e inhumanas de trabajo, la deficiente remuneración, junto con el desconocimiento de la preparación intelectual y profesional que poseían los inmigrantes, previa a su ubicación en España, logrando empleo en espacios laborales ajenos a los campos de formación. Preferencialmente, fueron identificados como opciones laborales, aquellos trabajos mecánicos que demandan un mayor esfuerzo de naturaleza física, por ejemplo, la construcción de vías y el servicio doméstico, oficios a los que no aplican regularmente los españoles.

Así mismo, la discriminación fue identificada por los inmigrantes como uno de los mayores motivos que generó estados emocionales de temor, angustia y ansiedad. La humillación, fue una tendencia altamente identificada en las relaciones humanas y que en muchas oportunidades se encontró en el trato con algunos españoles, particularmente personas mayores. También la xenofobia y el racismo son problemas identificados por los inmigrantes, aunque en un alto porcentaje de quienes conformaron la muestra en esta investigación, no lo vivieron de manera directa, sí identificaron formas discriminatorias que han observado hacia otros compatriotas inmigrantes, generadas por algunos españoles.

Ejemplos de discriminación, han sido registrados inclusive en los medios de comunicación nacional e internacional, porque han tenido despliegue por los altos niveles de agresividad y las prácticas vejatorias que han sufrido los latinos. Es un trato, considerado, según los testimonios, altanero, ofensivo y desafiante, que llega a la utilización de formas vejatorias contra algunos inmigrantes, trato en los que prevalecen los insultos y los ataques físicos. Se hará referencia a tres casos. El primero, en donde sin mediar discusión, un barcelonés ataca a una ecuatoriana en un tren ${ }^{6}$. En el segundo caso, un $\mathrm{Co}^{-}$

6 Noticia registrada en el periódico El País de España el 23 de octubre de 2007, en el que un barcelonés agrede sin mediar palabra a una joven ecuatoriana de 16 años. Insultos soeces como «zorra e inmigrante de mierda», dan cuenta de las acentuadas formas de xenofobia y discriminación. 
lombiano es atacado por un grupo de españoles ${ }^{7} \mathrm{y}$, en el tercero, una enfermera ecuatoriana es agredida por una doctora en Barcelona ${ }^{8}$.

Adicionalmente, en el contexto de la investigación realizada se pueden apreciar los espacios laborales como escenarios propicios para ejercer la discriminación. Las razones fundamentales están determinadas por la vulnerabilidad que aprovechan, en algunas oportunidades, los jefes [españoles] para amedrentar a los inmigrantes por no poseer una situación definida, en cuanto a la documentación que lo acredite como extranjero, con los permisos o contratos de trabajo necesarios. Igualmente los horarios extensos, la no organización de las condiciones de trabajo para poder disponer del descanso al que se tiene derecho como trabajador, las condiciones de vinculación laboral y la remuneración son expresamente diferentes con las de los españoles.

La Comisión Europea, en la obra Combatir la discriminación. Manual de formación, en relación a la discriminación, expresa lo siguiente: Discriminar significa diferenciar o dar trato diferente cuando no existen diferencias importantes entre las personas o las situaciones, así como dar trato idéntico a situaciones que en realidad son diferentes (2005: 14).

Igualmente la Carta de los Derechos Fundamentales de la Unión Europea, promulgada solemnemente en diciembre de 2000, dispone en el apartado 1 del artículo 21, lo siguiente: "Se prohíbe toda discriminación, y en particular la ejercida en razones de sexo, raza, color, orígenes étnicos y sociales, características genéticas, lengua, religión o convicciones, opiniones políticas o de cualquier otro tipo, pertenencia a una minoría nacional, patrimonio, nacimiento, discapacidad, edad u orientación sexual".

7 Noticia registrada en Noticias inmigrantes de noviembre 6 de 2007, en: http://madrepatria.blogspot. com/2007/11/cinco-jvenes-agreden-un-colombianoen.html. Se consignas formas agresivas como atropellar al colombiano con el carro o agredirlo físicamente generándole fracturas.

8 Noticia registrada en el diario Europa Press, noviembre 5 de 2007 con el titular: Multan a doctora por agredir y llamar "sudaca de mierda» a su enfermera, evento que sucedió el 14 de agosto de 2007.

\section{Creatividad y resiliencia en los procesos de adaptación a los nuevos contextos}

Teniendo en cuenta la estrecha relación entre los términos y procesos que implican las posibilidades de todo sujeto como son la creatividad y la resiliencia y, con el fin de valorar las principales formas de superación construidas por los participantes en la investigación para afrontar situaciones de dificultad o adversidad, a continuación se presenta el concepto de resiliencia, propuesto por Quiñones en su obra Resiliencia. Resignificación creativa de la adversidad:

Resiliencia es la capacidad del sujeto, que a partir de situaciones adversas, construye o reconstruye alternativas tanto del sí mismo como sujeto, como de los procesos relacionales y de las condiciones de los entornos particulares de convivencia en que se desenvuelve. Por la resiliencia, el sujeto es capaz de replantear nuevas miradas y posibilidades a sus actuaciones en el mundo, elaboración que logra mediante una fluidez de pensamientos, sentimientos y acciones de manera creativa. Es poder llegar a generar otras maneras de percibir y actuar en el mundo que ha sido transformado o destruido por los eventos traumáticos y/o adversos que afronta (2007: 79).

Indiscutiblemente, las condiciones de los dos grupos analizados en la investigación presentan diferencias significativas en cuanto a las razones que determinaron la movilidad humana y las condiciones en que la misma se efectuó, pero tanto en la población en condiciones de desplazamiento forzado como en el caso de los inmigrantes en España, se pudieron identificar expresiones de ingenio y creatividad que posibilitó a los participantes la construcción de alternativas de superación de dificultades y solución de problemas con el fin de lograr una adaptación a los nuevos contextos.

La resiliencia fue más explícita en los participantes que conformaron el grupo de personas en condiciones de desplazamiento forzado, esto se debe a la gravedad de los hechos -violentos y destructivosque han tenido que enfrentar. Lo anterior es característica fundamental de los eventos de adversidad.

A continuación se hará una breve relación de las principales manifestaciones resilientes. 
Uno de los temas en que más se presentó una tendencia de acciones efectivamente resilientes fue en el campo emocional, especialmente y como se expresó con anterioridad, para los integrantes de que conforman la muestra de la población en condiciones de desplazamiento forzado: personas y grupos familiares que han vivido episodios de destrucción por la presencia de hechos violentos, amenazas, torturas o muerte, que viven el destierro y el éxodo, evento que se fundamenta en la necesidad de protección, en donde "huir es salvar la vida". Adicionalmente, son seres humanos que han vivido situaciones de soledad y vacío emocional porque en un alto porcentaje se desplazan con hijos menores de edad, habiendo perdido al esposo(a) o desconociendo el paradero de hijos o hijas adolescentes que en muchas ocasiones han sido reclutados o desaparecidos por los grupos insurgentes.

Todas estas condiciones efectivamente son factores de gran adversidad que impulsan a los sujetos a la consolidación de formas resilientes para la superación creativa de las problemáticas vividas.

Cyrulnik, refiere el significado de los acontecimientos traumáticos y la respuesta resiliente que elaboran los sujetos, en los siguientes términos: "La respuesta resiliente es, pues, un comportarse antes que un comprender y asumir la herida, y un comportarse de tal índole que, antes que la herida, lo que el sujeto resiliente asume es su propia existencia como suya, como valiosa y como su propia responsabilidad" (2002: 250).

Por todo lo que se ha identificado previamente, el sujeto tiene que resarcir las condiciones personales y el tejido social en el que se encuentre. En esta medida, debe resignificar las experiencias de adversidad viviendo paralelamente la urgencia de la ubicación y adaptación en un contexto desconocido, a veces inhóspito, o en otras encontrando redes de apoyo para la solución inicial de condiciones de supervivencia.

Otro ejemplo en el que se puede apreciar la capacidad creativa es el relacionado con el manejo de la situación laboral.
Vale la pena establecer la comparación entre las condiciones económicas que poseía el grupo de inmigrantes en España, porque se presentaron situaciones muy variadas. Es así como un grupo de participantes contaba, en el momento de viajar, con un contrato previamente establecido, circunstancia que les aseguraba el trabajo y, por consiguiente, una estabilidad personal.

De la misma manera, otro grupo de participantes que tenía como proyecto fundamental realizar estudios con la subvención de gastos, ya fuera a nivel personal, familiar o institucional, no vivieron situaciones de angustia para la satisfacción de sus necesidades.

Igualmente un grupo más reducido emigró con un capital mínimo, condición que les deparaba más incertidumbre y que, a su vez, exigió a las personas una gran creatividad para la consecución de trabajo o la adaptación en condiciones reducidas y de grandes limitaciones económicas.

Por toda la anterior caracterización, en la situación de los inmigrantes que vivieron dificultades relacionadas con la parte económica y con el mercado laboral, se puede identificar fundamentalmente un gran esfuerzo y dedicación, porque la problemática se centra en enfrentar las formas discriminatorias, la aceptación de trabajos con jornadas laborales extenuantes y que no tienen la misma remuneración que sí tiene, por ejemplo, un español que desempeñe el mismo oficio. Todas éstas, son circunstancias que implican niveles de dificultad mas no se constituyen en formas de adversidad propiamente dicha.

A diferencia de la variedad de oportunidades referenciadas sobre los inmigrantes en España, en la problemática social del desplazamiento forzado, por las mismas condiciones que implican la gravedad de los hechos, las limitaciones y dificultades extremas propias de estos eventos y circunstancias, la resiliencia se puede apreciar permanentemente.

Algunos de los ejemplos más sobresalientes de creatividad, efectivamente resiliente, son las formas 
de obtención de fuentes de empleo que les permitiera una satisfacción de necesidades básicas como vivienda y alimentación. Lo anterior cobra mayor significado cuando las personas, que se encontraban en sus lugares de origen en condiciones de vida satisfactorias con ingresos suficientes, terrenos, cultivos y ganadería, han tenido que emprender una nueva vida, en condiciones económicas precarias, debido al destierro a que fueron sometidas.

Adicionalmente, en la mayoría de los episodios que se presentaron de desplazamiento forzado, en el momento de abandonar el lugar de residencia, las personas tuvieron que "huir" en condiciones mínimas, esto es, con algunos enseres y vestimenta básica o solamente con lo que portaban cuando se presentaron los episodios violentos. La pérdida de sus predios, elementos de agricultura y ganadería, les generó total caos por la misma vulnerabilidad de insolvencia económica a que se vieron abocados, situación que se agudiza por las grandes dificultades de consecución de trabajo en los nuevos contextos de destino.

Por todas las razones identificadas ante las condiciones de deprivación económica y las limitaciones que esta situación conlleva, la creatividad - como característica que hace posible los procesos de adaptación- fluye de manera sorprendente en las personas. Son formas de afrontar una realidad inmediata, de lograr una transformación ágil, persuasiva y eficiente ante situaciones y espacios desconocidos para las personas.

Las siguientes son las actividades mas utilizadas, que implican una gran creatividad para lograr la adaptación en los nuevos contextos: ventas callejeras de múltiples productos, preparación de una gran diversidad de comidas, aprendizaje de oficios para los cuales nunca han tenido un preparación previa, el aprovechamiento de oportunidades como la capacitación para el aprendizaje de actividades relacionadas con la confección de diferentes artículos relacionados con el vestuario (ropa femenina y masculina, zapatos, tejidos, entre otros), área de decoración expresada en elaboración de cajas y bolsas para empaque de regalos, trabajo en el campo del embellecimiento (corte de pelo, manicure, pedicure), organización de microempresas.

\section{Conclusiones}

- En las condiciones actuales de la humanidad, con las tendencias y realidades de la globalización, el multiculturalismo es un hecho presente en los diferentes contextos sociales, como formas de expresión de la movilidad humana. Ante las problemáticas sociales que ocurren en diferentes contextos, nos vemos abocados a una presencia permanente y a la vez fluctuante de una gran diversidad de culturas, con un bagaje de sentidos y significados sobre las propias dinámicas relaciones que se establecen por la interculturalidad.

- La construcción del tejido social en contextos de incertidumbre y complejidad, como es el caso de procesos de migración y desplazamiento forzado, demanda el reconocimiento en alteridad para una coexistencia en sociedades pluriculturales. Los procesos de asimilación, adaptación e integración de y a nuevas culturas, a partir del respeto mutuo ante la diversidad de esquemas de pensamiento, creencias y formas de vida, son prioritarios. Lo anterior requiere de una gran apertura mental y actitudinal para la concertación de nuevas dinámicas y formas estructurales de la sociedad.

- Parte de los imaginarios y representaciones sociales que poseen las personas, producto de la tradición cultural y del aprendizaje a través de diferentes fuentes, determina estereotipos que se constituyen en prejuicios que pueden limitar los procesos interactivos.

- Si bien en la investigación se hicieron explícitas respuestas de aceptación asumidas de forma espontánea y natural, en muchos testimonios se observa la percepción del rechazo por un sentimiento de invasión de la propia cultura por parte de los miembros de las sociedades receptoras. Estas reacciones de defensa, en oportunidades consensuadas, dan origen a la discriminación, mediante el rechazo silencioso caracterizado por la indiferencia 
y la exclusión, o a la agresión explícita ya sea verbal, física o psicológica.

- Las expresiones emocionales que acompañan las experiencias de ubicación en nuevos contextos, como formas de manifestación de la capacidad de afectación del ser humano, determinan como necesidad imperiosa una generación de redes de apoyo en los contextos receptores que posibiliten un acompañamiento como forma de apoyo preventivo ante el estres, la angustia, la ansiedad y el resentimiento que generan, especialmente en el caso de la población en condiciones de desplazamiento forzado, las vivencias traumáticas del desarraigo y la violencia.

- Las redes de apoyo, como alternativa prioritaria en contextos de incertidumbre y complejidad, posibilitan resarcir el tejido social a partir de la comunicación, la integración y el emprendimiento de acciones tendentes a la solución de situaciones que implican dificultad, alteración o destrucción. Mediante una red de apoyo se promueven mecanismos de ayuda humanitaria, no asistencialista, porque los integrantes de las redes, de manera activa, escuchan, comprenden, actúan, proponen, trasforman $y$, como proceso fundamental, participan en la resignificación y co-construcción de alternativas para la transformación de experiencias, situaciones y contextos.

- La indiferencia, la agresión, la discriminación y el abuso del poder se minimizan cuando se trabaja en las redes de apoyo social, pues el presupuesto básico es el "reconocimiento personal y del otro en alteridad". Es valorar, proteger y permitir ser como sujetos activos, pensantes y actuantes.

- El reto de los procesos educativos es abrir espacios que posibiliten una problematización para el análisis y cuestionamiento sobre las formas de jerarquización social existentes, que impiden el surgimiento de relaciones igualitarias y enriquecedoras, basadas en el reconocimiento y respeto mutuo, en la aceptación de la diferencia y en la implementación de una co-construcción de las relaciones sociales equitativas.

\section{Bibliografía}

Beristain, C. M. (2000). “Apoyo psicosocial en catástrofes colectivas. De la prevención a la reconstrucción". Caracas: Asociación Venezolana de Psicología Social -Avepso.

Bowlby, J. (1995). Vínculos afectivos: formación, desarrollo y pérdida. Madrid: Morata.

Conferencia Episcopal de Colombia. (2006). "Desafíos para construir nación. El país ante el desplazamiento, el conflicto armado y la crisis humanitaria 1995-2005". Oficina en Colombia del alto comisionado de las Naciones Unidas.

Consultoría para los Derechos Humanos y el Desplazamiento -CODHES-. (2007). "2007 Año de los Derechos de las Personas Desplazadas”, Cartagena, Colombia.

Convención de Ginebra. (1951). "Estatuto de los Refugiados”, capítulo 1, artículo 1, númeral 2. Ginebra, Suiza.

Csikszentmihalyi, M. (1998). Creatividad. El fluir de la psicología del descubrimiento y la invención. Barcelona: Paidós.

Cyrulnik, B. (2003). El murmullo de los fantasmas. Volver a la vida después del trauma. Barcelona: Gedisa.

Cyrulnik, B., Manciaux, M., Sánchez, E., Colmenares, M. E., Balegno, L. \& Olaya, M. (2002). La resiliencia. Desvictimizar la víctima. Cali: Casa editorial Rafue. CEIC.

Dailylife, Carl. (2005). “Combatir la discriminación. Manual de formación”. Comisión Europea.

El Mundo. (Agosto 24 de 2004). "La población española será superior a los 50 millones de persona en 2025" [en prensa]. Madrid.

Fajardo, D. (1999). Bases para una política de asentamientos humanos, prevención de los desplazamientos forzados y acceso a la tierra para los 
desplazados. Bogotá: Red de Solidaridad Social. Mimeo.

Fernández-Lasquetty. (2007) "Mujeres empresarias”. En Fusión Latina. Madrid: AvalMadrid.

Giuseppe, L. (2007). "X Congreso Internacional sobre Migraciones". Loreto, Italia.

Grimson, A. (2000). Interculturalidad y comunicación. Bogotá: Norma.

Herrán, A. de la. (1998). La conciencia humana. Hacia una educación transpersonal. Madrid: San Pablo.

Husserl, E. (1994). Problemas fundamentales de la fenomenología. Madrid: Alianza Editorial.

Malgesini, G. \& Gómez, C. P. (2004). Movimientos de población: migraciones y acción humanitaria. Barcelona: Icaria.

Manz, Ch. (2005). "Disciplina emocional". Barcelona: Paidós.

McKinley, B. (2006). "V Encuentro Iberoamericano sobre Migración y Desarrollo". Madrid, España.

Melillo, A. (2004). Resiliencia y subjetividad. Los ciclos de la vida. Buenos Aires: Paidós.

Morin, E. \& Baudrillard, J. (2004). La violencia del mundo. Barcelona: Paidós.

Naciones Unidas - Defensoría del Pueblo. Colombia. (2001). "Derechos de la población desplazada”. Bogotá.
Observatorio de los Derechos Humanos en Colombia. (2000). "Desplazamiento forzado: fuentes, causas y distribución geográfica”. Bogotá: Vicepresidencia de la República de Colombia, Boletín núm. 12.

Programa Andino de Derechos Humanos. (1984). "Coloquio sobre la protección internacional de los Refugiados en América Central, México y Panamá: Problemas jurídicos y humanitarios", Cartagena de Indias, Colombia.

Quiñones, R. A. (2007). Resiliencia. Resignificación creativa de la adversidad. Bogotá: Universidad Distrital Francisco José de Caldas.

Reina, M. (2007). Sobre los sentidos del multiculturalismo e interculturalismo. El Fuerte, México: Universidad Autónoma Indígena de México.

República de Colombia. Ley 387 de 1997, [por la cual se adoptan medidas para la prevención del desplazamiento forzado].

Rodrigo Alsina, M. (1999). La comunicación intercultural. Barcelona: Anthropos.

UNESCO. (1996). La educación encierra un tesoro. Buenos Aires: Santillana.

Wilber, K. (1979). La conciencia sin fronteras. Barcelona: Kairos.

Women's Commissions for Refugee Women and Children. (2002). Millones no vistos: La catástrofe del desplazamiento interno en Colombia. New York, USA. 